\title{
Estimation of cracking of reinforced concrete load-bearing construction structures at the stage of their technical inspection
}

\author{
Anna Malakhova* \\ Moscow State University of Civil Engineering, Yaroslavskoe shosse, 26, Moscow, 129337, Russia
}

\begin{abstract}
The article describes the process and causes of cracking of bearing reinforced concrete structures, revealed during the inspection of the technical condition of structural elements of buildings at the stage of their erection, at the stage of suspended construction and in the operational stage. The reasons for the appearance of cracks in reinforced concrete structures under force loads and climatic influences are analyzed. Possible reasons for the appearance of cracks in a monolithic reinforced concrete beam ceiling of a multi-storey building of a column structural system and in monolithic walls of an underground cylindrical reservoir, identified by the author of the article when inspecting the technical condition of these structures, are given. The relationship between the appearance of destructive cracks and the design errors of a monolithic reinforced concrete beam ceiling is shown. The complex nature of the causes of the appearance of cracks in the monolithic walls of the underground reservoir is revealed. The article describes the capabilities of the LIRA-CAD software package for determining the pattern and parameters of fracture-formation of reinforced concrete structures for subsequent comparison with the results of an inspection of the technical condition of structural elements of buildings and structures.
\end{abstract}

In accordance to construction norms, in order to ensure the safe operation of buildings and structures, their inspection is carried out for the subsequent assessment of the technical condition of load-bearing structures, for the determining of the correspondence of their actual performance to design decisions, to the requirements of the existing building codes, and to the conclusion of an expert examination. The inspection of buildings can be carried out during their erection, at the stage of suspension of construction, as well as at the stage of operation. The assessment of the technical condition of load-bearing structures is made on the basis of their visual, instrumental examination and verification checks.

Among the damages of building structures, which can significantly affect their work and function, a special place is occupied by cracks. Cracks, as the structural damages, are considered and accounted for when their width exceeds permissible values, or when they arise in places where their presence is unacceptable.

* Corresponding author: MalahovaAN@mgsu.ru 
In accordance to the rules for the design of concrete and reinforced concrete structures [1], the calculation for crack opening requires the fulfilment of the condition: $a_{c r c} \leq a_{c r c, u l t}$, In accordance to this condition, the crack opening width from external loads $a_{c r c}$ must not exceed the maximum permissible values $a_{c r c, u l t}$, which depend on the duration of the action of the loads, the class of the used reinforcement, as well as the requirements for waterproofness and safety of the reinforcement of the structures to be calculated.

The main parameter of crack formation is the crack opening width $a_{c r c}$. Additional parameters include the distance between cracks $l_{s}$ and the depth of crack opening. The character of the crack formation is also of interest, it causes the subsequent formation of fracture lines, along which the structures break down [2].

Part of the cracks can be attributed to technological, since their origin is associated with the technology of erecting of structural elements of the buildings. Such cracks, with their normative opening up to $0.1 \mathrm{~mm}$ [3], as a rule, do not have a significant effect on the bearing capacity of structures, but can create places for reducing their rigidity.

Figure 1a shows the appearance and shrinkage cracks with an opening width of up to $0.2 \mathrm{~mm}$ on the surface of the inner bearing wall of a monolithic multi-storey residential building.

At the stage of erection of buildings, cracks can arise as a result of various impacts on building structures: due to shrinkage of concrete, corrosion of concrete, reinforcement and embedded parts, due to thermal and mechanical influences, as a result of destruction of concrete by bio organisms. Already at the stage of the erection of the building in the bearing structures, cracks may appear, which opening width corresponds to or even exceeds the design width of the crack opening of the structural elements in the operational stage. This may indicate errors in the calculations, or about deviations from the design solution when constructing a building.

Figure $1 \mathrm{~b}$ shows a vertical crack with an opening width of $0.3 \mathrm{~mm}$ on the surface of a reinforced concrete pylon of the basement floor of an unfinished multi-storey monolithic residential building. In this case, we can expect a further increase in the width of the opening of the pylon crack during the continuation of the erection of the building with the further development of the process of corrosion of the longitudinal working reinforcement of the pylon.
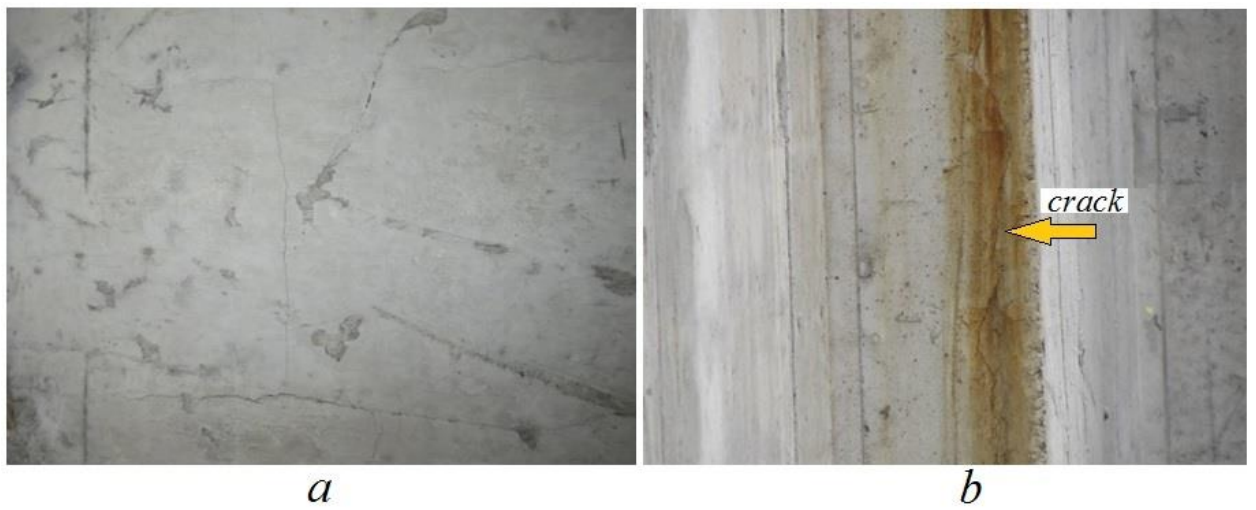

Fig.1. Shrink cracks with a width of opening up to $0.2 \mathrm{~mm}$ on the surface of the inner monolithic wall of the building (a), a vertical crack on the surface of a reinforced concrete pylon with a width of 0.3 $\mathrm{mm}$ opening and manifestations of corrosion of the armature (b)

On objects of unfinished construction, in the absence of conservation of the building, structural elements of the building are exposed to unfavorable climatic effects. Especially it concerns the structural elements of the unfinished upper floor of the building and the 
sections of slabs along the perimeter of the building, which are more exposed to moistening by atmospheric precipitation.

The practice of inspecting the technical condition of structural elements of unfinished buildings, left without proper preservation, indicates that the destruction of concrete and corrosion of the reinforcement often occurs on exposed surfaces of reinforced concrete structures [4].

In the operated buildings of the old construction, damages of reinforced concrete balcony slabs are identified everywhere during the inspection. Radical protection of reinforced concrete balcony slabs from moistening by atmospheric precipitation is the glazing of balconies. At present, when designing new and renovating old buildings, balconies are glazed [5].

Figure $2 \mathrm{a}$ shows the fracture at the upper surface of the monolithic ceiling slab unfinished building. Figure $2 \mathrm{~b}$ shows the typical defects of the concrete balcony slabs of the operated building.

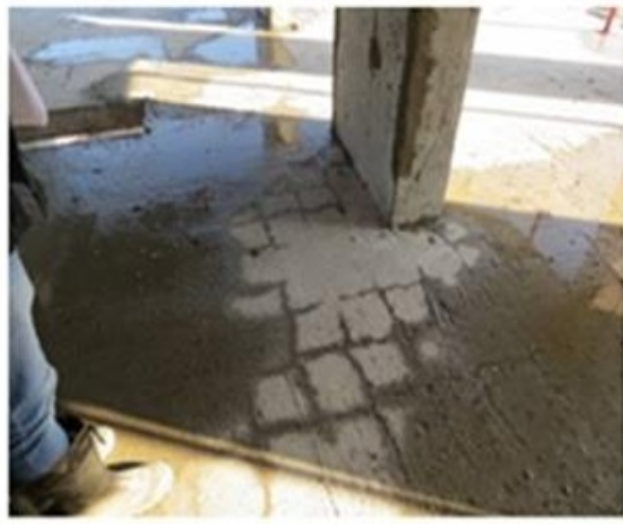

$a$

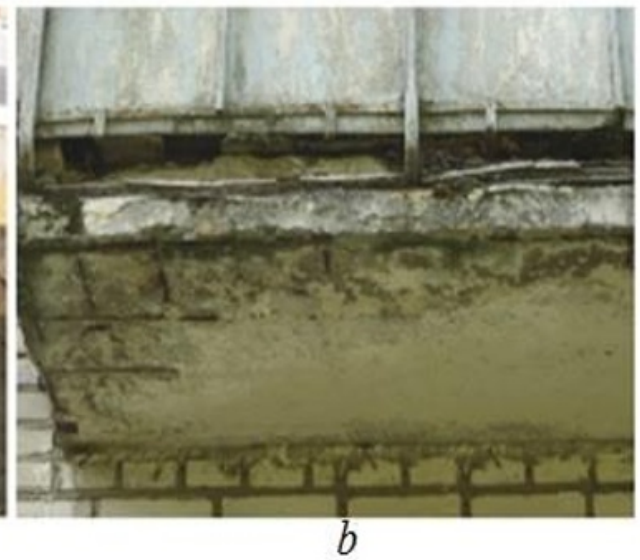

Fig.2. Destruction of the upper surface of the monolithic ceiling slab of unfinished building (a), typical defects of concrete balcony slabs of operated building (b)

The theory of reinforced concrete structures, supported by the results of scientific experiments and field observations, explains the reasons for the formation and development of cracks.

One of the main reasons for the initial cracking in concrete is its volumetric changes caused by moisture shrinkage. Unlike conditions where shrinkage develops freely, in the presence of constrained conditions, it leads to the appearance of internal stresses that exceed the tensile strength of concrete and cause the formation of cracks [6].

Shrinkage cracks in planar structures are distributed chaotically in volume, and in the construction of a complex configuration they concentrate at the interfaces of the elements [7].

The practice of inspection of reinforced concrete structures shows that shrinkage cracks can provoke the appearance of force cracks if they coincide in direction.

Cracks that have arisen in reinforced concrete at the stage of erection of buildings and structures due to corrosion of concrete, corrosion of reinforcement, pass along the corroded reinforcing reinforcement [8]. Under the influence of corrosion, the adhesion of the reinforcement to the concrete can be broken partially or completely.

When the coupling fails, the bearing capacity of the bent structural element decreases due to underutilization of the strength properties of the stretched reinforcement. Therefore, when conducting a inspection of bent reinforced concrete structures, there is often a need to 
assess the bearing capacity of the structure in the event of a failure in the adhesion of the reinforcement to the concrete.

Cracks from the force action are usually located perpendicular to the action of the principal tensile stresses. The nature of the cracks due to force depends on the static design of the structure, the type and nature of the load, the methods of reinforcement, the ratio of spans $[9,10]$.

In the bent reinforced concrete elements, the first cracks are formed in the zone of the greatest moment, the inclined cracks - on the lateral surface of the bearing sections of the beams in the zone of maximum transverse force.

The width of crack opening and the frequency of their location depend on the diameter of the reinforcement, the percentage of reinforcement, the class of reinforcement.

It should be noted that the appearance of single cracks with a weak reinforcement indicates an overload of the structure, while with strong reinforcement the appearance of a large number of cracks shows the normal operation of the structural element in the second stage of the stress-strain state.

The technical condition of the bent reinforced concrete structures can be judged both by the presence of cracks in the stretched and in the compressed zone of the structures. In the compressed zone of concrete, cracks appear that are parallel to the axis of the element, and there is also a detachment of concrete in this zone.

In stretched reinforced concrete elements under central tension, normal cracks are located along all facets of the section, and with eccentric stretching or compression, cracks occur on one stretched section face, as in the bending of an element.

When inspecting the technical condition of monolithic reinforced concrete structures, cracks are often associated with early demolition or loading of structures until they have set the design strength of concrete. These cracks are usually chaotically arranged and have different lengths.

For prefabricated hollow-core slabs, technological cracks in the ribs between the voids are characteristic, as well as longitudinal cracks on the upper surface of the slab along the voids. The first are formed when pulling punches, and the latter arise from the rupture of the concrete mixture when it vibrates.

An inspection of the technical condition of reinforced concrete structures of buildings and structures is aimed both at identifying defects, including cracks, and in identifying the causes of their appearance and the degree of their danger to the operation of facilities.

Figure 3 shows the constructive solution of a monolithic beam ceiling of a multi-storey building of a column structural system, during the examination of which cracks in slabs with an inadmissible opening width were detected.

At the same time, the character of the crack formation testified to the insufficient reinforcement of the slab of monolithic ceiling along the long side, although it is known that the rectangular slab, supported on the contour, mainly works on the smaller of the spans.

During the inspection, it was established that the reinforcement from the lower side of the beam ceiling slab was made with a knitted mesh of individual reinforcing bars $\varnothing 8 \mathrm{~A} 400$.

Moreover, the reinforcing bars of the knitted mesh running along the short side were installed with a pitch of $200 \mathrm{~mm}$, along a length of $300 \mathrm{~mm}$. Such a projected reinforcement suggested that the slab would work primarily on the smaller of the spans.

When analysing the structural solution of a monolithic beam ceiling, it was established that the principle of assigning cross-sectional dimensions of contour beams, depending on the applied load and the overlapping span, was not realized when designing the beam ceiling. All contoured floor beams had the same cross-sectional dimension $300 \times 500$ (h) $\mathrm{mm}$. 


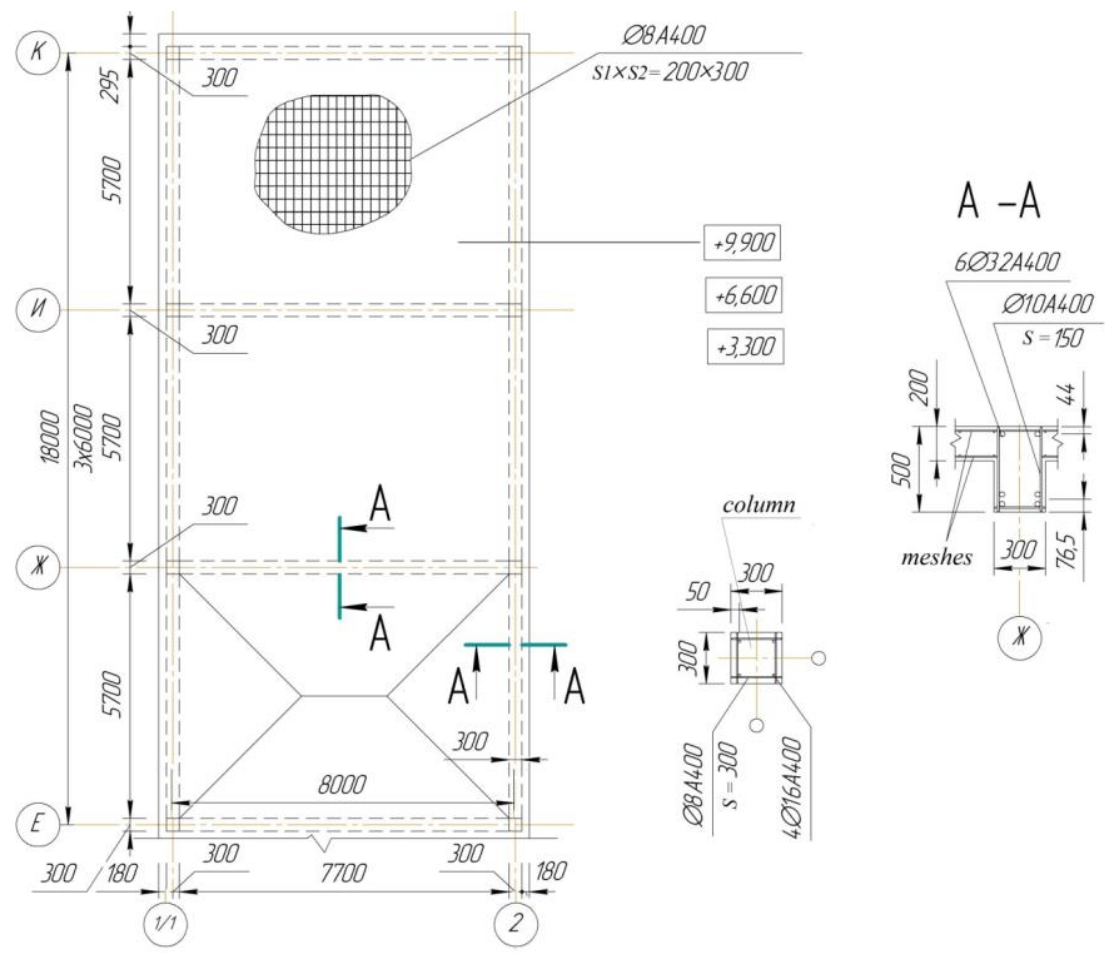

Fig.3. Constructive solution of the of the inspected monolithic beam ceiling

The assumed verification of the monolithic beam ceiling showed that the same crosssectional dimensions of the beams of both directions influenced the work of the monolithic slab under the load: the passing bending moment along the long side of the slab was greater than the moment along its short side, which led to the appearance of defects in the monolithic beam ceiling [11].

The practice of carrying out inspections of the technical condition of buildings and structures shows that it is not always possible to establish unambiguous reasons for the appearance of damages in the building structures of objects in operation. This is due, inter alia, to the impossibility of a full quantitative assessment of damage in the form of limited access to the construction structures of the exploited facilities, partial or complete absence of design and executive documentation for the work performed. In this case, the reasons for the appearance of damage may not be so obvious and often they are a result of simultaneous action of several factors.

Thus, during the inspection of the technical condition of the underground monolithic reinforced concrete cylindrical tank, damage was found to the exterior wall of the engine room in the form of annular cracks at a distance of about $2.5 \mathrm{~m}$ from the floor of the room. Through these cracks in the spring during the thawing of snow, water seeped into the engine room. Opening of the plaster layer allowed to estimate the opening width of annular cracks in the wall of a monolithic well. During the inspection in the summer, it was about $0.2 \mathrm{~mm}$. Figure 4 shows the location of the fracture in the reservoir design scheme, as well as the appearance of the internal surface of the wall with cracks in the engine room of the underground reservoir. 

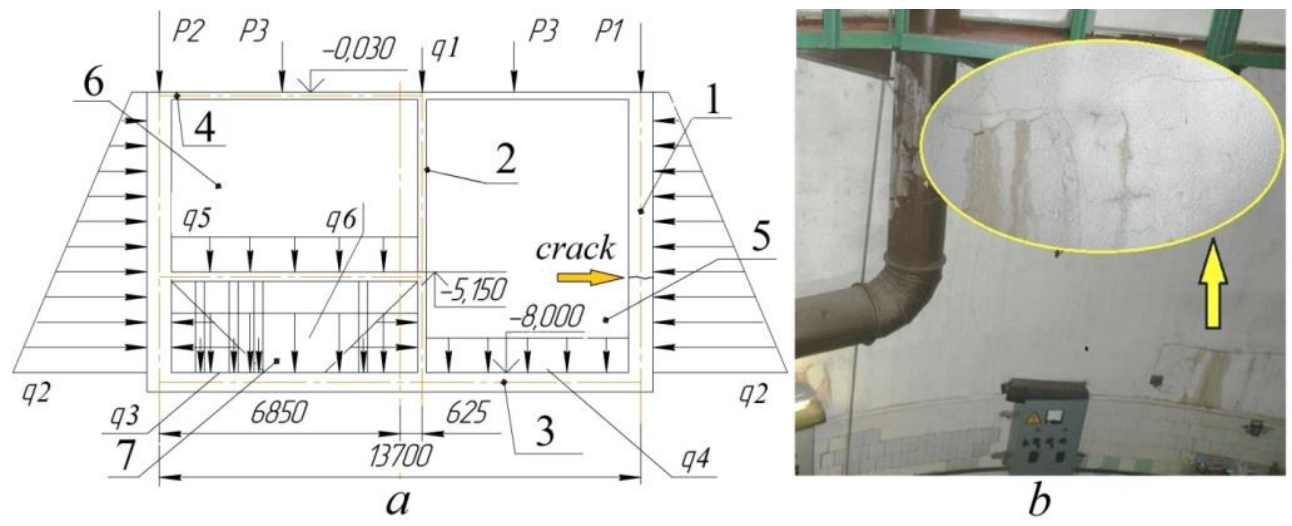

Fig.4. The location of the cracks in the calculated scheme of the underground reservoir (a); the view of an inner wall surface with cracks in the engine room of the reservoir (b): 1 - the outer wall of the reservoir; 2 - inner wall: 3 - bottom; 4 - coating; 5 - engine room, 6 - technical room; 7 - receiving reservoir

Complex analysis of the stressed-deformed state of the reinforced concrete underground reservoir together with the results of its visual and instrumental inspection, as well as the study of the available construction documentation, made it possible to point out possible causes of the appearance of ring cracks located at a height of $2.5 \mathrm{~m}$ from the floor of the room of the machine room.

So, the reason for the appearance of ring cracks in the wall of the reservoir and the infiltration of water into the reservoir room during the spring period was probably the coincidence of several factors: poor performance of the technological seam of the concreting in the level of the intermediate overlapping of the reservoir, the location of this seam at the place of the greatest tensile stresses of the inner edge of the wall; the pressure pattern of groundwater filtration during the rapid spring melting of snow [12].

It should be noted that modern software systems, including LIRA-CAD, allow performing verification calculations of the inspected reinforced concrete structures under various loads and impacts with obtaining a crack pattern and crack parameters. Computer modeling and comparison of the results of computer modeling with the results of a inspection of the technical state of the concrete structures of buildings and structures contribute to establishing the causes of the appearance of defects and their quantitative evaluation.

In Fig. 5 shows the results of a computer calculation to determine the pattern of cracking and mosaic of the width of the opening of the force cracks in a rigidly clamped three-sided flat slab with the use of the calculated processor LITERA and the panel-menu command CRACK CALCULATION of the LIRA-CAD program complex [14].

After the basic calculation of the floor slab, additional calculation using the LITER processor becomes available. The pattern of cracking of the structure can be obtained by drawing on the mosaic of the distribution of the principal tensile stresses N1, the graphical representation of the directions of the main axes of tensile stresses N1 and comparing the values of the principal tensile stresses with the normative value of tensile stresses for the concrete class adopted for the slab. Cracks are formed if N1> Rbt, n (Fig. 5a). 


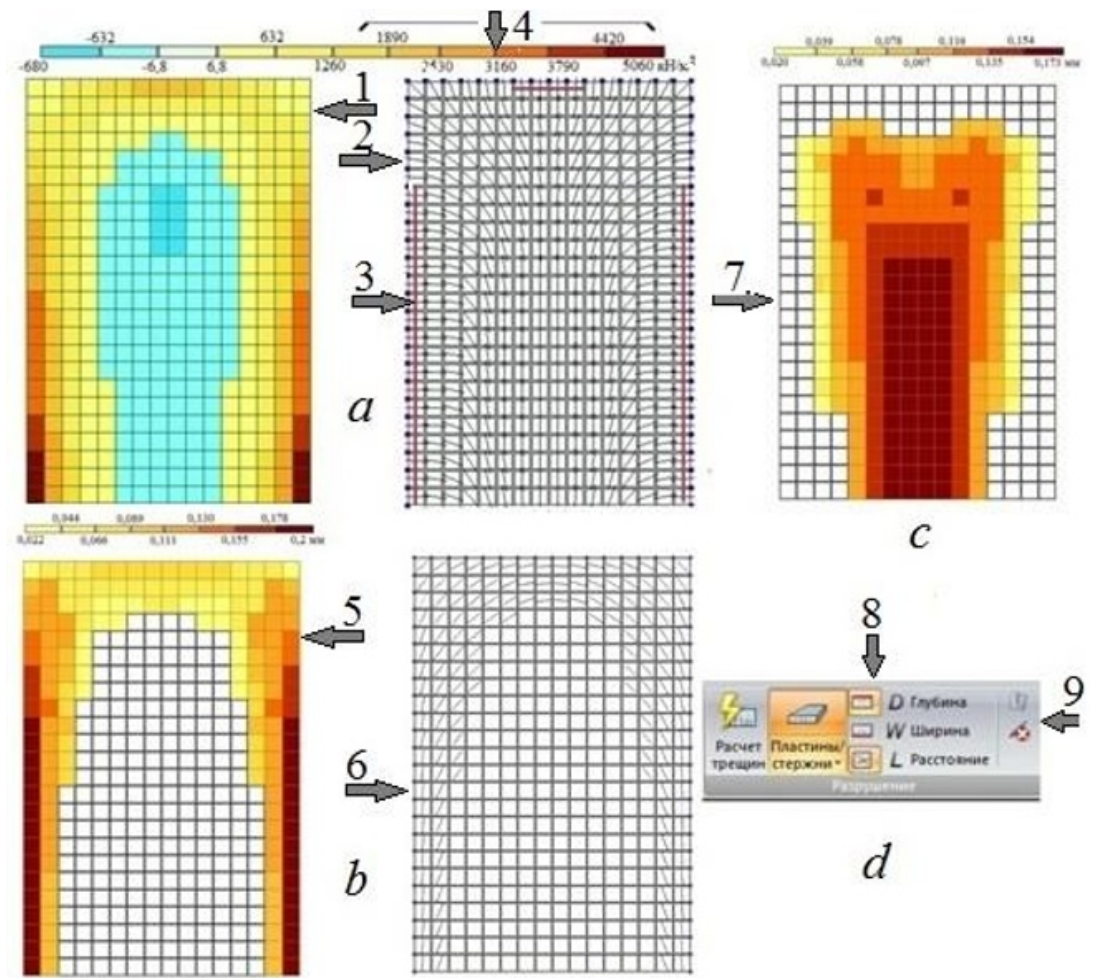

Fig.5. The results of calculation of the slab of the overlap rigidly fixed on three sides using the processor LITERA of LIRA-CAD (a) and the command CRACK CALCULATION of LIRA-CAD (b, c, d): 1 - the mosaic of the main voltages N1;2 - the direction of the main axes N1; 3 - location of cracks; 4 - cracking stresses (for the top layer of the slab); 5 - mosaic of the opening width; 6 - the direction of the cracks (for the top layer of the slab); 7 - the mosaic of the opening width (for the lower layer of the slab); 8 - the cracking; 9 - the destruction (the buttons on the panel-menu command CRACK CALCULATION)

Another and the main variant of computer fracturing calculations in the LIRA-CAD is the use of the CRACK CALCULATION command (Fig. 5 b, c, d). In addition to the main cracking parameter (crack opening width acrc,), additional cracking parameters can be obtained from the calculation using the CRACK CALCULATION command: the depth of crack opening and the cracks spacing $l_{s}$.

Calculation of crack formation for the upper and lower layers of the structure is performed in a nonlinear setting with modeling the process of the slab loading. In [14], it is recommended, when assigning a loading step, to take it unevenly with condensation at the time of the appearance of cracks, and also at the moments of the formation of the fracture lines of the slab before breaking it.

From the material of the article it can be seen that not always by the results of visual and instrumental inspection of buildings and structures and only on the basis of theoretical knowledge of the process of crack formation, it is possible to unambiguously identify its causes and assess the degree of danger of identified cracks for the subsequent exploitation of building structures. The article shows that the simulation of the work of reinforced concrete structures using modern software systems, including the LIRA-CAD, makes it possible to evaluate the influence of various factors on the process of crack formation in structures, to determine the parameters of crack formation, to investigate its character and the nature of the destruction of structures at various loads and impacts. 
Comparison of the results of computer simulation with the results of a technical inspection of reinforced concrete structures will allow to reliably estimate the cracking of structures and their condition in the preparation a conclusion on the possibility of continuing the construction of the facility or its operational reliability.

\section{References}

1. SP 63.13330.2012. Concrete and reinforced concrete structures. Basic provisions. Updated version of SNiP 52-01-2003

2. V.P. Agapov, I.I. Kovrigin, A.N. Malakhova, V.N. Savostyanov. Physically non-linear processes in building structures: textbook / V.P. Agapov, I.I. Kovrigin, A.N. Malakhova, V.N. Savostyanov; Ed. V.N. Savostyanov. - Moscow: Publishing House MISI-MSSU, pp.12-34, (2013)

3. SP 70.13330.2012. Bearing and enclosing structures. The updated version of SNiP 3.03.01-87

4. A.N. Malakhova, A.S. Balakshin. Damages of reinforced concrete bearing structures, manifested as a result of prolonged erection of buildings or a break in their construction. - Technology of the textile industry, 2 (374), pp. 214-219, (2018)

5. A.N. Malakhova. Causes and mechanism of operational damages of reinforced concrete balcony. // - PGS., 7, pp. 69-73, (2016)

6. N.G. Golovin, A.I. Bedov, A.S. Silant'ev, A.A. Voronov. Concrete shrinkage as a factor of development of defects in monolithic ceilings of multi-storey buildings // - PGS, 1, pp. 46-50, (2015)

7. N.G. Golovin, A.I. Bedov, A.S. Silantyev, A.A Voronov. Calculation of the resistance of monolithic reinforced concrete structures of multi-storey buildings, taking into account the development of deformation shrinkage // - Vestnik MGSU. -, 10, pp.36-42, (2012)

8. A.V. Nazarova, D.S. Kovalenko, K.S. Al-Marshdi. Effective ways of minimizing shrinkage cracking in cement concrete // Modern building materials, Lugansk, 2 (124), pp. 65-68, (2017)

9. O.V. Baydin. On the issue of the formation of cracks in reinforced concrete, subject to corrosion // - Bulletin of BSTU V.G. Shukhov, 4, pp. 20-24, (2012)

10. A.I. Bedov. Assessment of the technical condition, restoration and reinforcement of bases and building structures of operated buildings and structures. In 2 parts. Pl. Evaluation of the technical condition of bases and building structures. Training. - M., DIA, $704 \mathrm{p},(2014)$

11. A.N. Malakhova, D.Yu. Malakhov Estimating the load-bearing capacity of building structures for the inspection of the technical condition of buildings - M., MGSU, 96 p, (2015)

12. A.N. Malakhova. Features of the work of monolithic beam ceiling under load. Bulletin of MGSU, 11, pp. 50-57, (2013)

13. A.N. Malakhova. Possible complex causes of the appearance of cracks in the walls of an underground reservoir. - Construction and reconstruction, 1, pp.67-72, (2018)

14. A.S. Gorodetsky, I.D. Evzerov. Computer models of constructions. -Kiev: FACT Publishing House, - pp.197-203, (2005) 